\title{
The 5' regulatory sequence of the PMP22 in the patients with Charcot-Marie-Tooth disease
}

\author{
Elena Sinkiewicz-Darol, Dagmara Kabzińska, Izabela Moszyńska and Andrzej Kochański ${ }^{\bowtie}$ \\ Neuromuscular Unit, Mossakowski Medical Research Centre, Polish Academy of Sciences, Warszawa, Poland
}

\begin{abstract}
Little is known about the molecular background of clinical variability of Charcot-Marie-Tooth type 1A (CMT1A) disease and hereditary neuropathy with liability to pressure palsies (HNPP). The CMT1A and HNPP disorders result from duplication and deletion of the PMP22 gene respectively. In a series of studies performed on affected animal transgenic models of CMT1A disease, expression of the PMP22 gene (gene dosage) was shown to correlete with severity of CMT course (gene dosage effect). In this study we hypothesized that single nucleotide polymorphisms (SNPs) located within the 5' regulatory sequence of PMP22 gene may be responsible for the CMT1A/HNPP clinical variability. We have sequenced the $P M P 225^{\prime}$ upstream regulatory sequence in a group of $45 \mathrm{CMT1A}$ /HNPP patients harboring the PMP22 duplication (37) /deletion (8). We have identified five SNPs in the regulatory sequence of the PMP22 gene. Three of them i.e. $-819 \mathrm{C}>\mathrm{T},-4785 \mathrm{G}>\mathrm{T},-4800 \mathrm{C}>\mathrm{T}$ were detected both in the patients and in the control group. Thus, their pathogenic role in the regulation of the expression of the PMP22 gene seems not to be significant. Two SNPs i.e. $-4210 \mathrm{~T}>\mathrm{C}$ and $-4759 \mathrm{~T}>\mathrm{A}$ were found only in the CMT patients. Their role in the regulation of the PMP22 gene expression can not be excluded. Additionally we have detected the Thr118Met variant in exon 4 of the PMP22 gene, which was previously reported by other authors, in one patient. We conclude that the $5^{\prime}$ regulatory sequence of the PMP22 gene is conserved at the nucleotiode level, however rarely occurring SNPs variant in the PMP22 regulatory sequence may be associated with the gene dosage effect.
\end{abstract}

Keywords: PMP22 gene, gene dosage effect, Charcot-Marie-Tooth disease

Received: 27 May, 2010; revised: 03 September, 2010; accepted: 05 September, 2010; available n-line: 15 September, 2010

\section{INTRODUCTION}

Hereditary motor and sensory neuropathies (HMSN), also known as Charcot-Marie-Tooth disorders (CMT), represent a heterogenous group of disorders of the peripheral nervous system with a frequency 1:2500 (Skre, 1974).

Despite a wide genetic heterogeneity of CMT, all the patients affected with HMSN share a common phenotype characterized by slowly progressive wasting of the distal muscles of the lower and upper limbs accompanied by sensory disturbances (De Jonghe, 1998).

Among various forms of CMT, two subtypes, i.e. CMT1A and hereditary neuropathy with liability to pressure palsies (HNPP) represent the two most frequent entities.
CMT1A disease and HNPP are allelic disorders caused by duplication (CMT1A) or deletion (HNPP) of the PMP22 gene, respectively. The PMP22 gene has been mapped to chromosome 17 and is locatated in the 17p11.2-p12 region (Lupski et al. 1991; Raeymaekers et al., 1991). The PMP22 gene encodes peripheral myelin protein 22 (PMP 22) which is mainly expressed in myelinating Schwann cells (Snipes et al., 1992). Its transcript was also found during embryogenesis as a growth arrestspecific gene (gas-3) (Manfioletti et al., 1990).

The PMP22 gene spans approximately $40 \mathrm{~kb}$, contains four coding and two non-coding exons.

Expression of the PMP22 gene is regulated by two alternatively used promoters: promoter 1 containing exon $1 \mathrm{~A}$ and promoter 2 containing exon 1B (Suter et al,. 1994; Van de Wetering et al., 1999) (Fig. 1). High levels of the transcripts expressed from promoter 1 occur in the neural tissue and during myelin formation. Transcripts expressed from the second promoter were found in nonneural tissues such as lung, intestine, heart, and skeletal muscle (Manfioletti et al., 1990).

The altered PMP22 gene dosage may be responsible for clinical variability of CMT. Several studies on animal models in which mice and rats carry a variable number of PMP22 gene copies have demonstrated that PMP22 is a dosage-sensitive gene (Adlkofer et al., 1995; Sereda et al., 1996). A twofold increase in the PMP22 gene dosage in transgenic rats led to a morphological phenotype comparable to CMT1A, while transgenic mice carrying only one functional PMP22 allele develop a phenotype analogous to human HNPP (Adlkofer et al., 1995).

Severely affected CMT1A patients showed a higher mRNA level of the PMP22 gene in the sample taken from sural nerve biopsy compared to patients with a milder phenotype (Li et al., 2005).

Although both CMT1A and HNPP disorders are associated with a duplication or deletion of the PMP22 gene, respectively, they are characterized by a marked clinical variability. In fact, for unknown reasons about $20 \%$ of the individuals carrying the PMP22 gene deletion remain asymptomatic throughout life. In the majority of patients affected with HNPP, nerve palsies

$\bowtie$ e-mail: andko@cmdik.pan.pl

Abbreviations: Brn, brain-specific transcription factor; CMT, Charcot-Marie-Tooth disease; CREB, CAMP-responsive element binding protein; Egr, early growth-responsive gene; HNPP, hereditary neuropathy with liability to pressure palsies; Oct, octamer-binding protein; PAX, paired box transcription factor; PMP22, peripheral myelin protein 22; PRBS, progesterone receptor binding site; SNP, single nucleotide polymorphism; SREB, sterol regulatory element binding protein 


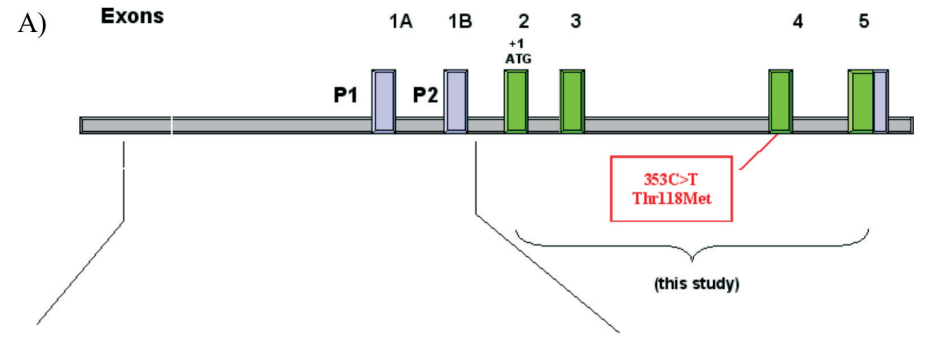

B)

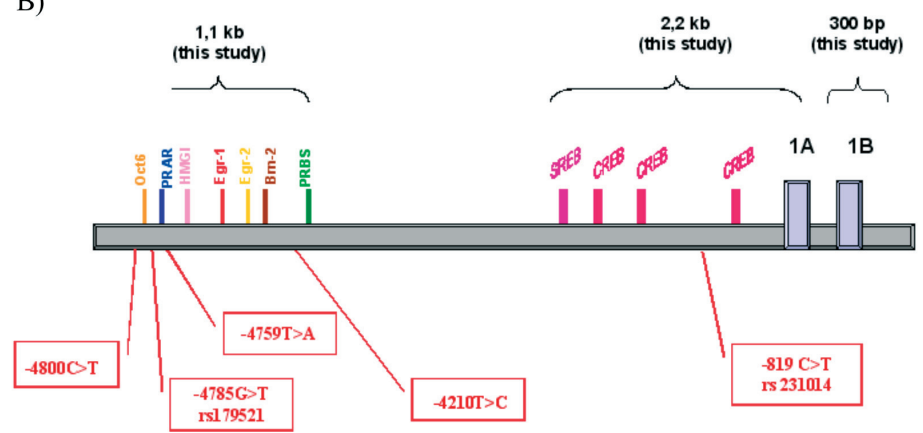

Figure 1. (A) Genomic organization of the PMP22 gene with position of promoters $P 1$, exon $1 \mathrm{~A}$ /promoter $1, \mathrm{P} 2$, exon $1 \mathrm{~B} /$ promoter 2

Four coding regions are schematically marked in green. The detected sequence variant is marked in red.

(B) 5' Regulatory sequence of PMP22 gene with marked analysed regions, potential binding sites for transcrption factors Oct6, PRAR, HMGI, Egr-1, Egr-2, Brn-2, PRBS, SREB, CREB and SNP variants detected in this study.

occur with a high frequency, whereas in others they may be provoked by some medical (rehabilitation) procedures even in the 7 th decade of life.

Similarly, in the CMT1A disease majority of the patients manifest with first symptoms in the early childhood, whereas other patients begin to suffer from CM$\mathrm{T} 1 \mathrm{~A}$ in the $6^{\text {th }}$ decade of life.

In some CMT1A patients, muscle wasting and weakness are not limited to the distal muscles but proximal muscles are also involved in the neuropathic process (De Jonghe, 1998).

Most studies have focused on genetic variants in the PMP22 coding sequence, which may influence clinical variability of CMT1A/HNPP patients.

The PMP22 gene regulatory sequence contains a number of putative binding sites for transcription factors and regulatory motifs which are known to play a role in myelination or to be expressed in Schwann cells like Krox20/Egr-2, Egr-1, Tst-1/Oct-6, Pax-3, Brn-2 peroxisome proliferator-activated receptor (PPAR), progesterone receptor binding site (PRBS), cAMP-responsive element binding protein 1 (CREBP), (Saberan-Djoneidi et al., 2000; Hai et al., 2001; Maier et al., 2003; Itou et al., 2009).

To the best of our knowledge, the 5 ' upstream regulatory sequence with the promoter of the PMP22 gene has been so far only partially analyzed (500 bp and $300 \mathrm{bp}$ ) in CMT patients without duplication/deletion of PMP22 gene (Nelis et al., 1998; Numakura et al., 2002).

In this study, we aimed to detect single nucleotide variants (SNPs) in 5' PMP22 regulatory sequence and two promoters $(3.6 \mathrm{~kb})$ and to determine whether these variants may be associated with the CMT1A/HNPP clinical variability.

\section{MATERIALS AND METHODS}

Forty five patients affected with CMT (37) /HNPP (8) were examined by the neurologists at the Neuromuscular Unit. At least three-generation family trees were constructed for all the patients. The clinical diagnosis of CMT/ HNPP was confirmed in all patients by electromyographic examination (EMG). Patients displaying symmetrical, generalized neuropathy involving upper and lower limbs were included in this study. All members of the CMT/HNPP affected families gave signed informed consent. The study was approved by the local Ethics Committee at the Warsaw Medical University (approval No. 120/2008.)

The control group consists of 100 unaffected individuals and was recruited from healthy individuals.

Genomic DNA was extracted from peripheral blood lymphocytes using salting-out procedure. The duplication/deletion of the PMP22 gene was confirmed using Real Time PCR (Q-PCR) (Aarskog \& Vedeler, 2000). The Q-PCR was performed in the multiplex assay, in which two TaqMan probes labeled with FAM (PMP22 gene) and VIC (human serum albumin gene) were used. The RT-PCR reaction was performed on the ABI-7500 RealTime PCR system (Applied Biosystems).

In a group of 45 CMT1A/HNPP patients four coding exons of the PMP22 gene and a $3.6 \mathrm{~kb}$ long $5^{\prime}$ regulatory sequence were amplified by PCR.

The PCR products were sequenced (performed in the forward and reverse orientation) using BigDye ${ }^{\mathrm{TM}}$ Terminator Version 3.1 x1.1 Ready Reaction Cycle Sequencing kit on the ABI 3730/xl Genetic analyzer (Applied Biosystems). PMP22 gene sequence was analyzed by comparing with reference sequences NM 000304.2 (transcript variant 1) and NM 153321.1 (transcript variant 2) in the Basic Local Alignment Search Tool (Blast NCBI - http://blast.ncbi.nlm.nih.gov/Blast.cgi).

In control group the PMP22 gene sequence was screened for the presence of DNA variants using two separate approaches, i.e. single strand conformation polymorphism analysis (SSCP) and heteroduplex analysis (HA).

In the SSCP and HA analyses, PCR products were separated on $8.6 \%$ acrylamide gels (49:1 acrylamide/ bisacrylamide). The gels were silver stained, dried and archivized. Direct sequencing analysis of the PCR products with an altered migration pattern was performed.

\section{RESULTS}

Analysis of the coding sequence of the PMP22 gene performed on the DNA samples obtained from 45 affected patients revealed a heretozygous sequence variant 353C $>\mathrm{T}$ Thr118Met in one patient. 
Table 1. Polymorphisms in the 5' regulatory sequence of PMP22 gene detected in this study

\begin{tabular}{lccc}
\hline Reference dbSNP (NCBI) & $\begin{array}{l}\text { Nucleotide change (Position }- \\
\text { from the ATG codon of exon 2) }\end{array}$ & Occurrence in the patients & Occurrence in controls \\
\hline rs231014 & $-819 \mathrm{C}>\mathrm{T}$ & $21 / 45$ & $48 / 100$ \\
- & $-4210 \mathrm{~T}>\mathrm{C}$ & $1 / 45$ & $0 / 100$ \\
- & $-4759 \mathrm{~T}>\mathrm{A}$ & $2 / 45$ & $0 / 100$ \\
rs179521 & $-4785 \mathrm{G}>\mathrm{T}$ & $24 / 45$ & $43 / 100$ \\
- & $-4800 \mathrm{C}>\mathrm{T}$ & $2 / 45$ & $1 / 100$ \\
\hline
\end{tabular}

A direct sequencing of the $2.2 \mathrm{~kb}$ regulatory sequence of the PMP22 gene performed on the DNA samples obtained from 45 affected patients revealed a sequence variant $-819 \mathrm{C}>\mathrm{T}$. This variant, previously detected and designated as rs231014, was present both in the homozygous and the heterozygous state with frequence of $50 \%$. We also detected the $-819 \mathrm{C}>\mathrm{T}$ variant in 48 healthy individuals in the control group consisting of 100 subjects (200 chromosomes) (Table 1).

Analysis of the $1.1 \mathrm{~kb}$ regulatory sequence of the PMP22 gene (from $-3790 \mathrm{bp}$ to $-4900 \mathrm{bp}$ ), was performed on the DNA samples obtained from 45 affected patients and the control group consisting of 100 subjects (200 chromosomes).

Sequencig analysis revealed four sequence variants $-4210 \mathrm{~T}>\mathrm{C},-4759 \mathrm{~T}>\mathrm{A},-4785 \mathrm{G}>\mathrm{T},-4800 \mathrm{C}>\mathrm{T}$.

The $-4210 \mathrm{~T}>\mathrm{C}$ sequence variant was present in the hemizygous state in one patient (Fig. 2). We did not detect this variant in the control group. Interestingly, a new $-4210 \mathrm{~T}>\mathrm{C}$ sequence variant was detected in the patient presenting with atypical clinical course of hereditary neuropathy with liability to pressure palsies (HNPP) (Fig. 2). In fact, this patient did not present any symptom of HNPP till the 7th decade of life. Surprisingly, the HNPP episode in this patient was triggered by a rehabilitation procedure in which median nerve at the wrist level was compressed.

The haplotype $-4759 \mathrm{~T}>\mathrm{A},-4785 \mathrm{G}>\mathrm{T},-4800 \mathrm{C}>\mathrm{T}$ was present in the hemizygous state in one family (Fig. 3). We did not detect this sequence variant in the control samples.

The $-4785 \mathrm{G}>\mathrm{T}$ sequence variant previously detected and designated as rs179521, was present in the homozygous and the heterozygous state with frequence of $50 \%$. This sequence variant and the $-4800 \mathrm{C}>\mathrm{T}$ was also found in the control group (Table 1). A third $-4759 \mathrm{~T}>\mathrm{A}$ sequence variant was detected in two related patients with phenotype of HNPP (Fig. 3). Interestingly, this SNP variant was not present in the 60 year-old father of the patient - II:3. In fact the father of the patient remained completely asymptomatic till the 6 -th decade of life. There is a possibility that the $-4759 \mathrm{~T}>\mathrm{A}$ variant absent in the patient II:3 harboring deletion of the PMP22 gene may be causative for the early expression of classical HNPP in the patients III:2 and III: 3 harboring heterozygous $-4759 \mathrm{~T}>\mathrm{A}$ sequence variant.

We have also sequenced the exon1B/promoter 2 of the PMP22. This analysis revealed no sequence variants.

\section{DISCUSSION}

In this study we have hypothesized that a marked clinical variability observed in the CMT1A/HNPP affected patients may be associated with the presence of the SNP sequence variants located in the $5^{\prime}$ regulatory sequence of the PMP22 gene.

In fact, the transgenic animals harboring variable number of the copies of the PMP22 gene were shown to display variable clinical severity of heritable peripheral neuropathy (Adlkofer et al., 1995; Sereda et al., 1996).

Similarly the CMT1A affected patients with high expression of the PMP22 gene detected in the sural nerve biopsies developed severe clinical course of CMT1A (Li et al., 2005).

Previously Nelis and colleagues screened a $500 \mathrm{bp}$ long 5' regulatory sequence of the PMP22 gene in a small
A)

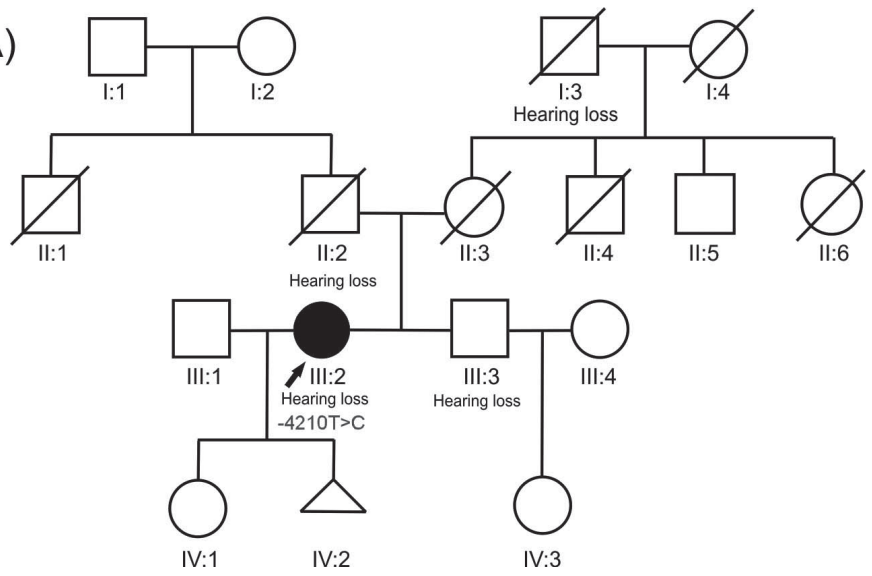

B)

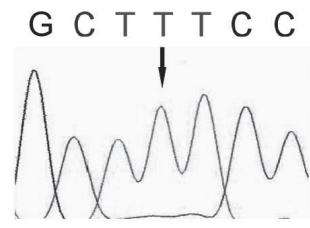

C)

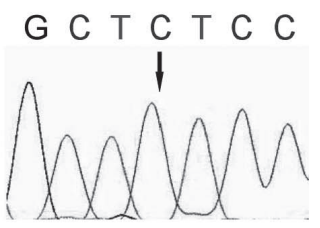

Figure 2. Family tree and results of sequencing analysis in an HNPP family with hearing impairment

(A) Pedigree of four-generation family with hearing loss and a sporadic case of HNPP. The arrow indicates the proband. Fragment of PMP22 gene regulatory sequence, (B) wild type sequence (C) hemozygous variant $-4210 \mathrm{~T}>C$ found in the proband (III: 2 ). 

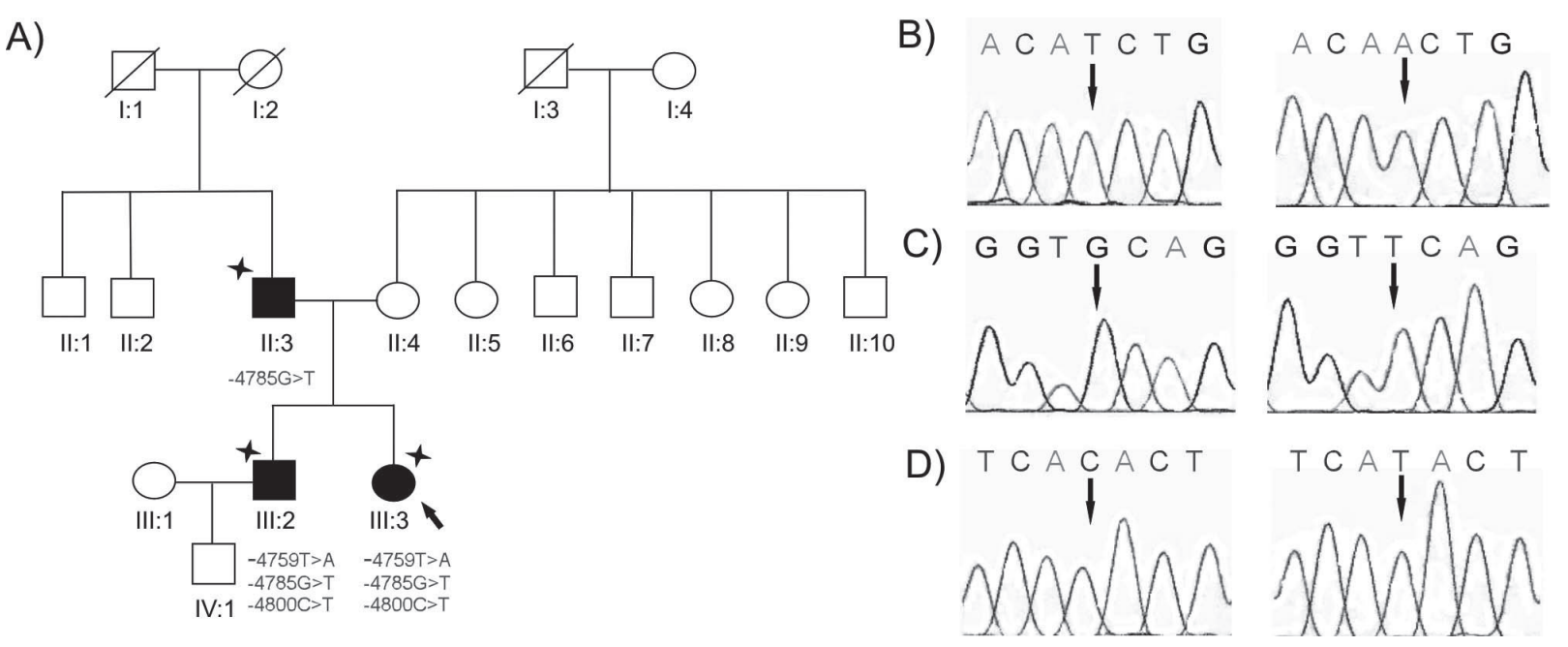

Figure 3. Family tree and results of sequencing analysis in HNPP family with variable age at onset

(A) Pedigree of a four-generation family HNPP family. The arrow indicates the proband and the asterisks DNA available for analysis. Fragment of PMP22 gene regulatory sequence with DNA variants: (B) $-4759 T>A,(C)-4785 G>T$, (D) $-4800 C>T$.

group of CMT1A patients. In this approach which may be characterized as a low mutation detection ratio procedure (single strand conformation polymorphism) only one $-141 \mathrm{C}>\mathrm{G}$ SNP variant was found in a single CMT affected patient (Nelis et al., 1998). To improve the mutation detection ratio we decided to screen the $5^{\prime}$ regulatory sequence of the PMP22 gene by direct sequencing.

Moreover we decided to extend the PMP22 regulatory sequence from $500 \mathrm{bp}$ to a region encompassing 3600 bp.

The extension of the analyzed 5 ' regulatory PMP22 region resulted from the analysis performed by Maier et al. (2003), in which numerous binding sites for transcription factors and regulatory motifs which are known to play a role in myelination of peripheral nervous system were detected.

Our analysis resulted in detection of five SNPs variants within 5 ' regulatory sequence of the PMP22 gene. Three of them i.e. $-819 \mathrm{C}>\mathrm{T},-4785 \mathrm{G}>\mathrm{T}$ and $-4800 \mathrm{C}>\mathrm{T}$ were detected both in the CMT patients and in the control group. Thus, tend to exclude the role of these polymorphisms in the regulation of the expression of the PMP22 gene.

We can not exclude that $-4210 \mathrm{~T}>\mathrm{C}$ sequence variant may play a regulatory role for the expression of the PMP22 gene (atypical clinical course of HNPP).

We aimed to test this hypothesis at the RNA level, but the proband and her family refused to cooperate with us in the studies of expression of the PMP22 gene.

In the patient with $-4759 \mathrm{~T}>\mathrm{A}$ similarly to the patient harboring the $-4210 \mathrm{~T}>\mathrm{C}$ variant we did not have opportunity to analyse expression of the PMP22 gene, since there is no reason to take sural nerve biopsy from the patients diagnosed at the DNA level.

Additionally we have identified in one CMT affected patient a recurrent Thr118Met harmless variant in the coding sequence of the PMP22 gene reported by numerous authors.

To conclude, our study shows that even extended 5' regulatory sequence of the PMP22 gene in CMT1A/ HNPP affected patients is highly conserved. The conserved 5' regulatory sequence of the PMP22 gene seems to be associated with a tight regulation of the dosage of this gene which was established to be a key pathogenic factor of the CMT1A/HNPP clinical variability. Our data indicate that PMP22 gene dosage may be regulated by other not yet analyzed factors.

\section{Acknowledgements}

This study was supported by a grant from the Polish Ministry of Science and Higher Education (NN 40227 63 36).

\section{REFERENCES}

Aarskog NK, Vedeler CA (2000) Real-time quantitative polymerase chain reaction. A new method that detects both the peripheral myelin protein 22 duplication in Charcot-Marie-Tooth type $1 \mathrm{~A}$ disease and the peripheral myelin protein 22 deletion in hereditary neuropathy with liability to pressure palsies. Hum Genet 107: 494-498.

Adlkofer K, Martini R, Aguzzi A, Zielasek J, Toyka KV, Suter U (1995) Hypermyelination and demyelinating peripheral neuropathy in Pmp22-deficient mice. Nat Genet 11: 274-280.

De Jonghe PJL (1998) The inherited neuropathies of the peripheral nervous system in the DNA era: genotype-phenotype correlations. PhD Thesis, University of Antwerp.

Hai M, Bidichandani SI, Patel PI (2001) Identification of a positive regulatory element in the myelin-specific promoter of the PMP22 gene. I Neurosci Res 65: 508-519.

Itou J, Suyama M, Imamura Y, Deguchi T, Fujimori K, Yuba S, Kawarabayasi Y, Kawasaki T (2009) Functional and comparative genomics analyses of pmp22 in medaka fish. BMC Neuroscience 10: 60.

Li J, Bai Y, Ghandour K, Qin P, Grandis M, Trostinskaia A, Ianakova E, Wu X, Schenone A, Vallat JM, Kupsky WJ, Hatfield J, Shy ME (2005) Skin biopsies in myelin-related neuropathies: bringing molecular pathology to the bedside. Brain 128: 1168-1177.

Lupski JR, de Oca-Luna RM, Slaugenhaupt S, Pentao L, Guzzetta V, Trask BJ, Saucedo-Cardenas O, Barker DF, Killian JM, Garcia CA, Chakravarti A, Patel PI (1991) DNA duplication associated with Charcot-Marie-Tooth disease type 1A. Cell 66: 219-232.

Maier M, Castagner F, Berger P, Suter U (2003) Distinct elements of the peripheral myelin protein 22 (PMP22) promoter regulate expression in Schwann cells and sensory neurons. Mol Cell Neurosci 24: 803-817.

Manfioletti G, Ruaro ME, Del Sal G, Philipson L, Schneider C (1990) A growth arrest-specific (gas) gene codes for a membrane protein. Mol Cell Biol 10: 2924-2930.

Nelis E, De Jonghe P, De Vriendt E, Patel PI, Martin JJ, Van Broeckhoven $C$ (1998) Mutation analysis of the nerve specific promoter of the peripheral myelin protein 22 gene in CMT1 disease and HNPP. J Med Genet 35: 590-593.

Numakura C, Lin C, Tohru Ikegami T, Guldberg P, Hayasaka K (2002) Molecular analysis in Japanese patients with Charcot-Marie-Tooth disease: DGGE analysis for PMP22, MPZ, and Cx32/GJB1 mutations. Human Mutat 20: 392-398.

Raeymaekers P, Timmerman V, Nelis E, De Jonghe P, Hoogendijk JE, Baas F, Barker DF, Martin JJ, De Visser M, Bolhuis PA et al. 
(1991) Duplication in chromosome 17p11.2 in Charcot-Marie-Tooth neuropathy type 1a (CMT 1a). The HMSN Collaborative Research Group. Neuromusc Disord 1: 93-97.

Saberan-Djoneidi D, Sanguedolce V, Assouline Z, Levy N, Passage E, Fontes M (2000) Molecular dissection of the Schwann cell specific promoter of the PMP22 gene. Gene 248: 223-231.

Sereda M, Griffiths I, Pühlhofer A, Stewart H, Rossner MJ, Zimmerman F, Magyar JP, Schneider A, Hund E, Meinck HM, Suter U, Nave KA (1996) A transgenic rat model of Charcot-Marie-Tooth disease. Neuron 16: 1049-1060.

Skre H (1974) Genetic and clinical aspects of Charcot-Marie-Tooth's disease. Clin Genet 6: 98-118.
Snipes GJ, Suter U, Welcher AA, Shooter EM (1992) Characterization of a novel peripheral nervous system myelin protein (PMP-22/ SR13). J Cell Biol 117: 225-238.

Suter U, Snipes GJ, Schoener-Scott R, Welcher AA, Pareek S, Lupski JR, Murphy RA, Shooter EM, Patel PI (1994) Regulation of tissue-specific expression of alternative peripheral myelin protein-22 (PMP22) gene transcripts by two promoters. I Biol Chem 269: 25795-25808.

Van de Wetering RAC, Gabreels-Festen A, Kremer H, Kalscheuer VM, Gabreels F, Mariman EC (1999) Regulation and expression of the murine Pmp22 gene. Mamm Genome 10: 419-422. 